Case Report

\title{
Short but continuous natural pain during meditation sittings for depression treatment: a case report
}

\author{
Mingwei Huang ${ }^{*}, 1$ \\ 1Department of Biomolecular Chemistry, School of Medicine and Public Health, \\ University of Wisconsin-Madison \\ Madison, WI 53706
}

*To whom correspondence should be addressed:

Dr. Mingwei Huang

1135 Biochemistry Building

420 Henry Mall

University of Wisconsin-Madison

Madison, WI 53706

Telephone: (608) 265-5689

E-mail: mhuang38@wisc.edu

Running Title: short but continuous pain and depression

Keywords: pain, depression, treatment, meditation, synaptic plasticity and homeostasis, nerve stimulation 
Case Report

\begin{abstract}
Major depressive disorder (MDD) is a common mental disorder, which results in seriously impaired condition in the patients and great global disability burden. In light of its quite diverse etiologies, comorbidity with many other diseases, and complex underlying pathology, it has been a great challenge to understand the physiological basis of MDD, which may be a complex of related diseases, rather than a single one. In addition to the partial understanding of MDD, the individual heterogeneities among patients may render the development of a universal treatment an elusive goal. But studying how each of currently available treatments affects the disease can generate useful information to stratify patients into different subtypes for individualized treatments. In this case report, we present the first report of repeated success of using meditation as the only treatment of MDD, compared to initial success but no remission with other conventional antidepressants on the same patient. We hypothesized that the short but continuous natural pain during one-hour meditation sittings has the therapeutic effect to treat depression in the case of this patient and potentially others with MDD. This special opportunity of eliminating tremendous heterogeneity among different individuals has enabled us to probe deeply into the potential mechanism of depression treatments and the complex physiology of depression itself, both of which have likely profound implications in the treatment of other MDD patients as well. More importantly, this case report helps us dissect one specific component of meditation for its longknown and well-established benefit against depression.
\end{abstract}


Case Report

\section{Introduction}

Major depressive disorder (MDD) is a common mental disorder, which results in seriously impaired condition in the patients and great global disability burden $(1,2)$. Conventional antidepressants often take weeks or months to demonstrate full effect, not all patients have a good response, relapse rate is high even for those effective treatment, and only a subset of patients achieved remission, raising the question of either the complexity of the disease or the effectiveness of those antidepressants $(3,4)$.

In light of its quite diverse etiologies, comorbidity with many other diseases, and complex underlying pathology, it has been a great challenge to understand the physiological basis of MDD, which may be a complex of related diseases, rather than a single one. In addition to the partial understanding of MDD, the individual heterogeneities among patients may further render the development of a universal treatment an elusive goal. But studying how each of the currently available treatments affects the disease can generate useful information to stratify patients into different subtypes for individualized treatment as an ultimate goal (5).

\section{Case report}

A 30-year-old, right-handed man with recurrent MDD (DSM-5 diagnostic code 296.3) (6) was admitted to the GHC-SCW Capitol Regent mental health clinic (Madison, Wisconsin) for his worsening depressive episodes that rendered him unable to work. Symptoms included depressed mood, anhedonia, altered sleeping pattern and appetite, and impaired cognitive capabilities. The first diagnosis of MDD was made in 2012 (Table 1) and contributing factors might include seasonal changes and some workrelated stress. The occurrence of his depression showed a strong seasonal pattern, with a start in late fall or early winter and an end in late spring or early summer. Past medical history was otherwise unremarkable. The patient's father had a history of alcohol abuse and mental illness (no clinical diagnosis, but likely schizophrenia), which also led to his premature death at the age of 44 . Written informed consent was obtained from the patient for publication of this report.

A timeline of diagnosis and treatment is listed in Table 1. Several points of particular significance have been made as below:

1. Worsening of allergic response to pollens happened concomitantly with the development of depression symptoms, whereas disappearance of the allergy reaction always took place at the beginning of depression recovery.

2. There were good and fast responses to multiple medications including sertraline, a combination of sertraline and bupropion, and psilocybin, but remission was not achieved.

3. Other adjustment methods were tried by the patient, such as psychotherapy, exercises, light therapy, and nutritional supplements, but none resulted in consistent improvement. 
Case Report

4. Meditation practice repeatedly led to the patient's recovery from depression in 2017 and 2018.

Two key observations have contributed to our hypothesis that the Short but Continuous natural Pain (SCP) during one-hour meditation sittings has the therapeutic effect to treat depression in the case of this patient and potentially others with MDD.

First, the acute relief of allergic reactions after the first one-hour sitting without major movements during the meditation retreat in 2018, which marked the start of improved depression symptoms, did not take place at earlier times of the retreat, when the patient performed multiple one-hour sittings each day but with some movements to relieve leg pain. The critical difference between the one therapeutic sitting and previous nontherapeutic ones was continuous pain perception. This first observation indicated that the pain in this specific context is sufficient to reduce depression symptoms.

Second, the patient relapsed at the end of 2017 even though he maintained meditation sittings on most days, but with shorter time and adjusting movements during almost all sittings, and thus rarely experienced SCP. This second observation suggested that SCP is necessary for the therapeutic effect against depression.

\section{Discussion}

To our knowledge, this is the first report of repeated success of using meditation as the only treatment of MDD, compared to initial success but no remission with other conventional antidepressants on the same patient. This special opportunity of eliminating tremendous heterogeneity among different individuals has enabled us to probe deeply into the potential mechanisms of depression treatments and the complex physiology of depression itself, both of which have likely profound implications in the treatment of other MDD patients as well. Our proposed hypothesis above is counterintuitive to the current understanding of the relationship between depression and chronic pain, so a more comprehensive review has been provided in a separate publication due to space limit (7).

Pain and depression are inter-connected through the endocrine, immune, and nervous systems. These systems communicate with each other and contribute a dynamic equilibrium and system homeostasis, which are exemplified at different levels, such as Th1/2 balance and synaptic plasticity $(8,9)$. But dysregulation triggered by stress can lead to shifts in balance and the system may not be able to return to homeostasis and exemplified again at different levels, such as Th1/2 imbalance and synaptic malfunctions (10).

Multiple factors influence the function of the immune and nervous systems, such as inflammatory cytokines, monoamines, and neural synapses, whose imbalance has been proposed to be involved in the development of depression $(5,10-13)$. Ultimately, the system reaches maladaptative states that have symptomatic presentations. This could help explain increased allergic sensitivity to pollen during depression and remarkably decreased allergic response to pollen as the start of recovery from depression observed 
Case Report

in our case. In this vein, ketamine as well as other new fast-acting antidepressants could exert their fast antidepressant effect through their ability to manipulate body's response to external and internal stimuli (14-24). Similarly, conventional antidepressants and psilocybin might function through monoamine related pain pathways (25-27). However, shifting maladaptative states of the body make it an elusive goal to achieve remission, which could be supported by research findings such as distinct changes in depressive symptoms upon ketamine administration between depressed and healthy subjects (28).

In the case of our patient's repeated recovery from depression using meditation, SCP could well function as a sustained stressor and stimulate the hypothalamic-pituitaryadrenal axis and the sympathetic nervous system, which lead to glucocorticoid (GC) release and anti-inflammatory effects, or could act through the parasympathetic nervous system and the cholinergic anti-inflammatory pathway (reduction in production of inflammatory cytokines and relief of allergic responses) $(9,11,29,30)$. The inability to adapt is one unique property of pain sensation from other senses, which would be dampened by constant stimulations (31). In this sense, SCP lasts long enough to trigger significant changes in the pain pathways and potentially benefit depression recovery despite shifting maladaptative states of the body, through fine tuning the interconnected endocrine, immune, and nervous systems. Similarly, exercise, fish oil consumption, controlled breathing, and other relaxation therapies have been implicated in increasing vagus nerve activity and decreasing pro-inflammatory cytokine release, consistent with observed clinic benefits of vagus nerve stimulation against depression $(9,32-34)$. Last but not least, Meditation associated pain has also been described by others (35).

Acute pain can be useful to trigger reflex to prevent injury, whereas chronic pain is generally detrimental, but what lies in between? SCP may exhibit different properties from those two types of pain and represent an exciting new research area that has been largely neglected to date. Our hypothesis remains to be proved and verified in other MDD patients and the proposed potential mechanisms merit future investigation. 
Case Report

\section{Contribution and statement of conflicts}

Conceived and designed research $(\mathrm{MH})$; wrote and revised manuscript $(\mathrm{MH})$.

The authors report no biomedical financial interests or potential conflicts of interest. 
Case Report

Table 1. History of treatment and related symptoms in a case of recurrent MDD

\begin{tabular}{|c|c|}
\hline $\begin{array}{c}\text { Time } \\
\text { period }\end{array}$ & Depression related symptoms and treatment \\
\hline $\begin{array}{c}\text { Nov } 2011 \\
\text { - May } \\
2012\end{array}$ & $\begin{array}{l}\text { Fatigue, but complete blood count normal and TSH only slightly above the } \\
\text { normal range } \\
>\text { Spring pollen allergy and cetirizine prescribed } \\
>\text { First diagnosis of MDD, single episode, moderate on Apr 13, } 2012 \\
\text { Initial four weeks of treatment with Sertraline } 50 \mathrm{mg} / \text { day resulted in no } \\
\text { depression relief, so dose increased to } 100 \mathrm{mg} / \text { day starting on May } 1 \text { and } \\
\text { depression symptoms subdued almost completely within several hours after } \\
\text { taking the increased dose of Sertraline } \\
>\text { Depression recovery witnessed by both primary physician and psychiatrist } \\
>\text { Sertraline stopped around Aug } 2012 \\
>\text { Depression free until Nov } 2012\end{array}$ \\
\hline $\begin{array}{c}\text { Nov } 2012 \\
-\mathrm{Apr} \\
2013\end{array}$ & $\begin{array}{l}\text { Visit of primary physician on Nov 20,2012 due to depression symptoms } \\
\text { Resuming sertraline } 100 \mathrm{mg} / \text { day resulted in no depression relief } \\
>\text { Diagnosis of recurrent major depression on Apr 8, 2013 } \\
\text { Addition of bupropion } 150 \mathrm{mg} / \text { day to sertraline } 100 \mathrm{mg} / \text { day from Apr } 24, \\
2013 \text { and depression symptoms subdued almost completely within } 36 \text { hours } \\
\text { after taking the medication } \\
>\text { Depression recovery witnessed by psychiatrist }\end{array}$ \\
\hline $\begin{array}{c}\text { May } 2013 \\
\text { - Sep } \\
2015\end{array}$ & $\begin{array}{l}>\text { Continued medication of bupropion } 150 \mathrm{mg} / \text { day and sertraline } 100 \mathrm{mg} / \text { day } \\
\text { Depressive symptoms during winter and spring (seemingly less severe) and } \\
\text { recovery in summer and fall } \\
>\text { Concurrent allergy reaction to pollens in the spring } \\
>\text { Visit of psychiatrist on May 8, } 2014 \text { due to recurrent depression symptoms } \\
>\text { Pollen allergy confirmed in a lab test on May } 16,2014 \\
>\text { Stop of medications after consultation with psychiatrist on Sep 3, } 2015 \\
>\text { Depression free until Dec } 2015\end{array}$ \\
\hline $\begin{array}{l}\text { Dec } 2015 \\
\text { - Jun } \\
2016\end{array}$ & $\begin{array}{l}>\text { Resuming medication of bupropion } 150 \mathrm{mg} / \text { day and sertraline } 100 \mathrm{mg} / \text { day } \\
\text { resulted in no depression relief } \\
>\text { Visit of psychiatrist on Jan } 29,2016 \text { due to recurrent depression symptoms } \\
>\text { Changed medication of bupropion } 300 \mathrm{mg} / \text { day and sertraline } 100 \mathrm{mg} / \text { day } \\
\text { after visit of psychiatrist on Mar } 10,2016 \text { resulted in no depression relief } \\
>\text { Concurrent allergy reaction to pollens in the spring } \\
>\text { Changed medication of bupropion } 300 \mathrm{mg} / \text { day and duloxetine } 30 \mathrm{mg} / \text { day } \\
\text { after visit of psychiatrist on May } 3,2016 \text { resulted in no depression relief } \\
>\text { Initiated psychotherapy with Joshua Olson, LMFT on May } 11,2016 \\
>\text { Initiated micro-dosing with psilocybin-containing mushroom on May 26, } \\
2016 \text { and noticed recovery from depression within } 24 \text { hours } \\
>\text { Antidepressants stopped from May 28, } 2016 \text { and micro-dosing stopped } \\
\text { from Jun } 29,2016 \\
>\text { Depression recovery witnessed by therapist and depression free until Dec } \\
\text { 2016 }\end{array}$ \\
\hline
\end{tabular}


Case Report

\begin{tabular}{|c|c|}
\hline $\begin{array}{c}\text { Dec } 2016 \\
\text { - Apr } \\
2017\end{array}$ & $\begin{array}{l}>\text { Resuming micro-dosing with psilocybin-containing mushroom from Dec } 12 \text {, } \\
2016 \text { resulted in no depression relief } \\
>\text { Restarted psychotherapy with Joshua Olson, LMFT on Jan 6, } 2017 \text { due to } \\
\text { recurrent depression } \\
>\text { Resuming medication of bupropion } 150 \mathrm{mg} / \text { day and duloxetine } 30 \mathrm{mg} / \text { day } \\
\text { after visit of primary physician (Sarah Spolum, PA-C) on Jan } 9,2017 \\
\text { resulted in no depression relief } \\
>\text { Changed medication of bupropion } 300 \mathrm{mg} / \text { day and duloxetine } 60 \mathrm{mg} / \text { day } \\
\text { after visit of primary physician on Feb 6, } 2017 \text { resulted in no depression } \\
\text { relief } \\
>\text { Changed medication of bupropion } 450 \mathrm{mg} / \text { day and duloxetine } 60 \mathrm{mg} / \text { day } \\
\text { after visit of psychiatrist on Mar } 14,2017 \text { resulted in no depression relief } \\
>\text { Changed medication of bupropion } 450 \mathrm{mg} / \text { day and duloxetine } 40 / 20 \\
\text { mg/day after visit of psychiatrist on Apr } 12,2017 \text { due to low blood pressure } \\
>\text { Concurrent allergy reaction to pollens in the spring } \\
>\text { All medications stopped before the meditation retreat of Apr } 19-30,2017 \\
\text { and noticed recovery from depression from May 1, 2017 } \\
>\text { Meditation maintained daily but with compromised practice } \\
>\text { Depression recovery witnessed by primary physician and depression free } \\
\text { until Dec } 2017\end{array}$ \\
\hline $\begin{array}{c}\text { Dec } 2017 \\
-\mathrm{Apr} \\
2018\end{array}$ & $\begin{array}{l}\text { Restarted psychotherapy with Joshua Olson, LMFT on Dec 11, } 2017 \text { due to } \\
\text { recurrent depression } \\
>\text { Started Liothyronine } 25 \mathrm{mg} / \text { day due to hypothyroidism after a visit of } \\
\text { psychiatrist on Dec } 13,2017 \text { and a lab test the following day } \\
>\text { Addition of fluoxetine } 10 \mathrm{mg} / \text { day to Liothyronine } 25 \mathrm{mg} / \text { day after visit of } \\
\text { primary physician on Dec } 22,2017 \text { resulted in no depression relief } \\
>\text { Changed medication of fluoxetine } 10 \mathrm{mg} / \text { day and Liothyronine } 12.5 \mathrm{mg} / \text { day } \\
\text { on Jan } 30,2018 \text { due to abnormally high T3 } \\
>\text { Changed medication of fluoxetine } 20 \mathrm{mg} / \text { day to Liothyronine } 12.5 \mathrm{mg} / \text { day } \\
\text { from Jan } 31,2018 \text { after visit of psychiatrist Graham Cody, MD resulted in no } \\
\text { depression relief }\end{array}$ \\
\hline
\end{tabular}


Case Report

\section{References:}

1. Kessler RC, Berglund P, Demler O, Jin R, Koretz D, Merikangas KR, et al. (2003):

The Epidemiology of Major Depressive Disorder: Results From the National Comorbidity Survey Replication (NCS-R). JAMA. 289: 3095-3105.

2. Murray CJL, Vos T, Lozano R, Naghavi M, Flaxman AD, Michaud C, et al. (2012):

Disability-adjusted life years (DALYs) for 291 diseases and injuries in 21 regions, 1990-2010: a systematic analysis for the Global Burden of Disease Study 2010. Lancet. 380: 2197-2223.

3. Insel TR, Wang PS (2009): The STAR ${ }^{\star} D$ Trial: Revealing the Need for Better Treatments. PS. 60: 1466-1467.

4. Rush AJ, Trivedi MH, Wisniewski SR, Nierenberg AA, Stewart JW, Warden D, et al. (2006): Acute and Longer-Term Outcomes in Depressed Outpatients Requiring One or Several Treatment Steps: A STAR*D Report. AJP. 163: 1905-1917.

5. Yohn CN, Gergues MM, Samuels BA (2017): The role of 5-HT receptors in depression. Molecular Brain. 10: 28.

6. Association AP (2013): Diagnostic and Statistical Manual of Mental Disorders, 5th

Edition: DSM-5, 5 edition. American Psychiatric Publishing.

7. Huang M (2018): Short but Continuous Natural Pain for Depression Treatment and Beyond. . doi: 10.20944/preprints201805.0411.v1.

8. Zunszain PA, Anacker C, Cattaneo A, Carvalho LA, Pariante CM (2011):

Glucocorticoids, cytokines and brain abnormalities in depression. Prog Neuropsychopharmacol Biol Psychiatry. 35: 722-729.

9. Tracey KJ (2009): Reflex control of immunity. Nature Reviews Immunology. 9: 418428. 
Case Report

10. Najjar S, Pearlman DM, Alper K, Najjar A, Devinsky O (2013): Neuroinflammation and psychiatric illness. Journal of Neuroinflammation. 10: 816.

11. Hodes GE, Kana V, Menard C, Merad M, Russo SJ (2015): Neuroimmune mechanisms of depression. Nature Neuroscience. 18: 1386-1393.

12. Duman RS, Aghajanian GK (2012): Synaptic Dysfunction in Depression: Potential Therapeutic Targets. Science. 338: 68-72.

13. Jeon SW, Kim YK (2016): Neuroinflammation and cytokine abnormality in major depression: Cause or consequence in that illness? World Journal of Psychiatry. 6: 283-293.

14. Lapidus KAB, Levitch CF, Perez AM, Brallier JW, Parides MK, Soleimani L, et al. (2014): A randomized controlled trial of intranasal ketamine in major depressive disorder. Biol Psychiatry. 76: 970-976.

15. DiazGranados N, Ibrahim LA, Brutsche NE, Ameli R, Henter ID, Luckenbaugh DA, et al. (2010): Rapid Resolution of Suicidal Ideation After a Single Infusion of an N-Methyl-D-Aspartate Antagonist in Patients With Treatment-Resistant Major Depressive Disorder. J Clin Psychiatry. 71: 1605-1611.

16. Price RB, losifescu DV, Murrough JW, Chang LC, Al Jurdi RK, lqbal SZ, et al. (2014): Effects of ketamine on explicit and implicit suicidal cognition: a randomized controlled trial in treatment-resistant depression. Depress Anxiety. $31: 335-343$.

17. Zarate CA, Singh JB, Carlson PJ, Brutsche NE, Ameli R, Luckenbaugh DA, et al. (2006): A Randomized Trial of an N-methyl-D-aspartate Antagonist in TreatmentResistant Major Depression. Arch Gen Psychiatry. 63: 856-864. 
Case Report

18. Berman RM, Cappiello A, Anand A, Oren DA, Heninger GR, Charney DS, Krystal JH (2000): Antidepressant effects of ketamine in depressed patients. Biological Psychiatry. 47: 351-354.

19. Murrough JW, losifescu DV, Chang LC, Al Jurdi RK, Green CE, Perez AM, et al. (2013): Antidepressant Efficacy of Ketamine in Treatment-Resistant Major Depression: A Two-Site Randomized Controlled Trial. AJP. 170: 1134-1142.

20. Sleigh J, Harvey M, Voss L, Denny B (2014): Ketamine - More mechanisms of action than just NMDA blockade. Trends in Anaesthesia and Critical Care. 4: 7681.

21. Singh JB, Fedgchin M, Daly EJ, De Boer P, Cooper K, Lim P, et al. (2016): A Double-Blind, Randomized, Placebo-Controlled, Dose-Frequency Study of Intravenous Ketamine in Patients With Treatment-Resistant Depression. AJP. appi.ajp.2016.16010037.

22. Singh JB, Fedgchin M, Daly E, Xi L, Melman C, De Bruecker G, et al. (2016): Intravenous Esketamine in Adult Treatment-Resistant Depression: A DoubleBlind, Double-Randomization, Placebo-Controlled Study. Biol Psychiatry. 80: $424-431$.

23. Zanos P, Gould TD (2018): Mechanisms of ketamine action as an antidepressant. Molecular Psychiatry. 23: 801-811.

24. Loix S, De Kock M, Henin P (2011): The anti-inflammatory effects of ketamine: state of the art. Acta Anaesthesiol Belg. 62: 47-58.

25. Tylš F, Páleníček T, Horáček J (2014): Psilocybin--summary of knowledge and new perspectives. Eur Neuropsychopharmacol. 24: 342-356. 
Case Report

26. Nichols DE (2016): Psychedelics. Pharmacol Rev. 68: 264-355.

27. Fein A (2012): Nociceptors and the perception of pain. University of Connecticut Health Center. 4: 61-67.

28. Nugent AC, Ballard ED, Gould TD, Park LT, Moaddel R, Brutsche NE, Zarate CA (2018): Ketamine has distinct electrophysiological and behavioral effects in depressed and healthy subjects. Molecular Psychiatry. 1.

29. Murison R (2016): Chapter 2 - The Neurobiology of Stress. In: al'Absi M, Flaten MA, editors. Neuroscience of Pain, Stress, and Emotion. San Diego: Academic Press, pp 29-49.

30. (Ron) de Kloet ER, Joëls M (2013): Stress Research: Past, Present, and Future. In: Pfaff DW, editor. Neuroscience in the 21st Century: From Basic to Clinical. New York, NY: Springer New York, pp 1979-2007.

31. Cervero F (2012): Understanding Pain: Exploring the Perception of Pain. MIT Press.

32. Breit S, Kupferberg A, Rogler G, Hasler G (2018): Vagus Nerve as Modulator of the Brain-Gut Axis in Psychiatric and Inflammatory Disorders. Front Psychiatry. 9. doi: 10.3389/fpsyt.2018.00044.

33. Kong J, Fang J, Park J, Li S, Rong P (2018): Treating Depression with Transcutaneous Auricular Vagus Nerve Stimulation: State of the Art and Future Perspectives. Front Psychiatry. 9. doi: 10.3389/fpsyt.2018.00020.

34. Howland RH (2014): Vagus Nerve Stimulation. Curr Behav Neurosci Rep. 1: 64-73. 35. Goleman D, Davidson RJ (2017): Altered Traits: Science Reveals how Meditation Changes Your Mind, Brain, and Body. Penguin. 